\title{
Litter and deadwood water retention processes in a temperate mixed forest
}

\section{Other Conference Item}

Author(s):

Floriancic, Marius (1); Allen, Scott Thomas (i); Molnar, Peter (i)

Publication date:

2021-04

Permanent link:

https://doi.org/10.3929/ethz-b-000526141

Rights / license:

Creative Commons Attribution 4.0 International

Originally published in:

EGUsphere, https://doi.org/10.5194/egusphere-egu21-15217 
EGU21-15217

https://doi.org/10.5194/egusphere-egu21-15217

EGU General Assembly 2021

(c) Author(s) 2022. This work is distributed under

the Creative Commons Attribution 4.0 License.

\title{
Litter and deadwood water retention processes in a temperate mixed forest
}

\author{
Marius G. Floriancic ${ }^{1,2}$, Scott T. Allen ${ }^{3}$, and Peter Molnar ${ }^{2}$ \\ ${ }^{1}$ ETH Zürich, Institute of Terrestrial Ecosystems, Zürich, Switzerland (floriancic@ifu.baug.ethz.ch) \\ ${ }^{2}$ ETH Zürich, Institute of Environmental Engineering, Zürich, Switzerland \\ ${ }^{3}$ University of Nevada, Dept. of Natural Resources and Environmental Science, Reno, USA
}

Countless studies have demonstrated ways in which forests and trees affect catchment water balances. Water balance differences between forested and non-forested landscapes are often attributed to characteristics related to trees' ability to take up and transpire water, as well as their ability to intercept precipitation. However, another potentially important characteristic of forests that has been largely overlooked in hydrologic studies is the retention and accumulation of debris, litter and deadwood on the forest floor. Here we leverage ongoing measurements at the new hillslope laboratory "Waldlabor" in Zurich, Switzerland, where water retention in forest litter, deadwood and the top soil layer has been investigated using frequent field campaigns and innovative new sensing techniques.

Several approaches were used to determine the maximum storage capacity as well as the storage dynamics of different types and layers of litter. In-lab saturation experiments revealed the maximum storage capacity of various litter types (i.e., leaf and needle litter). Those values were also supported with field pre- and post- rainfall sampling campaigns to determine in-situ litter storage dynamics, as well as to understand the interplay between litter interception and soil-water recharge. Importantly, recharge was often substantially smaller at plots with litter, compared to those without litter. The storage and water retention capacity of deadwood samples was measured in the field by logging the diurnal differences in deadwood weight over a six month period. Dew and fog deposition during the night led to larger water availability for evaporation during the day. We measured increased humidity at sensors in the forest at 1 and $3 \mathrm{~m}$ heights respectively, compared to the humidity outside the forest. Daily weight measurements over eight weeks of 40 deadwood pieces at our forest site revealed differences in the storage capacity depended on the degree of decomposition. Additionally, we found that water stored in forest floor spruce cones (daily measurements of 20 pieces) actively contributed to evaporation fluxes.

The combination of continuous sensor measurements (soil moisture, deadwood water content), field measurements (litter and deadwood grab samples) as well as laboratory work (saturation experiments) revealed the water storage and retention capacity of litter and deadwood in a typical temperate mixed forest and their contribution to evaporation. These measurements are one component of the new ETH Zürich "Waldlabor" research infrastructure, which also includes 
measurements of precipitation, xylem water, soil water, groundwater, and discharge amounts, isotope ratios, and other chemical characteristics. 